\title{
El peso de la violencia en los orígenes de la guerra civil de 1936-1939
}

\author{
Gabriele Ranzato \\ Profesor de H. ${ }^{a}$ Contemp. en el Dpto. de H. ${ }^{a}$. Universidad de Pisa (Italia) \\ The Importance of Violence at the Origins of the Spanish Civil \\ War of 1936
}

\begin{abstract}
RESUMEN
La gran cantidad de violencia que se desata en España en el período que va desde la victoria electoral del Frente Popular hasta el golpe militar contribuyó sin duda a hundir el país en la guerra civil.

Pero de qué manera? Una parte de la

historiografía opina que en el origen de aquella violencia hubo sobre todo un plan desestabilizador concebido por la derecha. Pero los atentados falangistas, no siendo dirigidos indiscriminadamente contra la población sino sólo contra militantes de la izquierda, no pudieron engendrar en la opinión pública desconfianza hacia el gobierno antifascista y provocaron en cambio una intensificación de sus medidas represivas.

Los efectos más desestabilizadores

fueron en realidad producidos por las actuaciones de las «milicias rojas» que, sobre todo en el campo, impusieron por la violencia o la amenaza de ella ocupaciones de tierras y condiciones contractuales que resultaban insoportables no solo para los grandes terratenientes y empresarios, sino que sobre todo para los más modestos. La

falta de neutralidad del gobierno en reprimir la violencia, su tolerancia hacia la actuación de las milicias de izquierda,
\end{abstract}

\section{SUMMARY}

The large amount of violence which broke loose in Spain, in the period between the electoral victory of the Popular Front and the military coup d'etat, certainly concurred to plunge the country into civil war. But how exactly did it happen? Many historians suggest that at the roots of that violence there was, mainly, a right-wing destabilizing scheme. In actual fact, the Falangist attacks did not hit indiscriminately the entire population but only and exclusively left-wing activists; so they did not breed mistrust in the Antifascist government but, rather, led to a hardening of the government's repressive measures. The most destabilizing effects were generated by the actions of the «red militias" who, above all in rural areas, imposed land takeovers and intolerable contract conditions not only to large landowners and businessmen, but often to small operators as well. The lack of government impartiality in cracking down on violence, its tolerance of leftist mobs, brought about a drift to the right of the more centrist voters of the Popular Front. Already alarmed by government social policies much more radical than those set forth in the electoral platform, frightened by the unrestrained deeds of the far-leftist 
provocaron un desplazamiento hacia la derecha de los electores más moderados del Frente Popular. Ya preocupada por la política social del gobierno — mucho más radical de la que se había perfilado en el programa electoral-, asustada por la incontrolada actuación de las milicias de

la extrema izquierda, la opinión pública moderada, aun cuando no apoyó el golpe, lo aceptó pasivamente.

$$
\begin{array}{r}
\text { PALABRAS CLAVE } \\
\text { violencia - desestabilización - milicias - } \\
\text { opinión pública - golpe }
\end{array}
$$

militias, the moderate public opinion who did not support the military coup remained, nonetheless, passive in the face of it.

\section{KEY WORDS}

violence - destabilization - militias - public

opinion - coup d'état

Toda la violencia política que ha caracterizado los primeros años de la Segunda República pese a su advenimiento tan pacífico, se puede considerar una larga premisa a la guerra civil de 1936. Pero la violencia que se va fraguando o se desata a partir de la victoria electoral del Frente Popular quizás se podría juzgar no sólo una premisa, sino una causa directa de la guerra civil misma. Sabemos que ya al día siguiente de esa victoria electoral algunos generales empezaron a conspirar para abatir la República; es decir que conciben un plan de violencia extrema para acabar con el gobierno del Frente Popular y con el régimen democrático. En el ámbito de la violencia no ha habido una condición más importante para que la guerra civil estallara.

Sin embargo, ni la violencia planeada en la conspiración, ni todo el conjunto de violencias concretas que se realizaron en aquellos meses fueron unas condiciones suficientes para ir a la guerra civil. Cuando los generales empezaron a conjurar el destino de España no estaba ya escrito y la guerra civil no era ya inevitable. Para que fuera inevitable era preciso que una serie de otros factores consolidaran sus intenciones y favorecieran la realización de sus propósitos.

Conspirar no bastaba, y tampoco bastaba tener el apoyo de las clases dominantes, es decir de aquellas clases cuyos intereses económicos y de poder se veían afectados por la democracia y por la limitación de sus riquezas, que el Frente Popular, sobre todo a través de la Reforma Agraria, iba a realizar. También el general Sanjurjo en 1932 había conspirado y había tenido el apoyo de las clases dominantes. $Y$ había fracasado. $Y$ no se puede decir que su fracaso fue sobre todo un hecho «técnico». Desde el punto de vista de la técnica del golpe también el de los «cuatro generales» se quedó muy lejos de la perfección. A Sanjurjo le faltaron sobre todo otros apoyos sociales. Básicamente, desde el punto de vista social se quedó con las clases dominantes, y esto se reflejó en el hecho de que, a pesar de las muchas simpatías de las que gozaba en los medios castrenses, encontró un limitado respaldo dentro del mismo ejército. 
A los "cuatro generales» que conspiraban les hacía falta por lo tanto tener el apoyo de una base social más amplia y que al mismo tiempo se desgastara el soporte político-social del que disfrutaban sus enemigos. Les hacía falta contar no sólo con la determinación a sostenerlos de los que habían votado para el Bloque Nacional - cosa que no era nada segura; ya que una cosa es votar, otra cosa es comprometerse con un golpe- sino también con el restringimiento de la base social con que había contado el Frente Popular para conseguir su éxito electoral.

Del cambio de orientación de una parte de la opinión pública que había votado a las izquierdas encontramos una breve pero clara indicación en el libro de Julián Zugazagoitia, Guerra y vicisitudes de los españoles, que, como es sabido, el ex-ministro de Gobernación del primer gobierno Negrín escribió en su corto exilio parisino antes de ser entregado a Franco por la policía alemana. En este relato, que bien se puede considerar «el más valioso de los escritos desde entonces por ningún dirigente de la República» ${ }^{1}$, Zugazagoitia escribe: «La victoria electoral, que no había sido tan rotunda como para menospreciar la fuerza de las derechas, quiso ser aprovechada sobre la marcha [por el FP] (...). Una parte de la opinión que había concedido el sufragio a las izquierdas se sintió arrepentida de su acto. Lamentaba no habérselo dado a la CEDA».2

Esta afirmación, admirablemente objetiva por parte de un hombre recién salido de la lucha, es tan importante que merece subrayarse que ella se puede considerar absolutamente certera, no pudiéndose encontrar ninguna razón que empujase Zugazagoitia a alejarse de la verdad sobre este punto. ${ }^{3}$ Por otro lado, si él dejaba imprecisada, con hablar de «una parte de la opinión», la relevancia del fenómeno, es indudable que ni siquiera lo habría mencionado de no ser de notable trascendencia. Y de hecho ese cambio de la opinión pública —-probablemente constituida en gran mayoría por clases medias, aunque no sólo- sí lo era, ya que no sólo implicaba que aquella mayoría relativa de votos que le había asegurado la victoria a la coalición de las izquierdas se había restringido aun más ${ }^{4}$, sino que sobre todo indicaba que se había restringido también el respaldo social con que podía contar el Frente Popular. Lo cual sin duda favorecía los planes de los Molas y de los Francos, porque si bien es evidente que arrepentirse de haber votado al Frente Popular no conllevaba necesariamente apoyar directamente al golpe, pero sí implicaba

1 S. JULIÁ, prólogo a la última edición de J. ZUGAZAGOITIA, Guerra y vicisitudes de los españoles, Tusquets Editores, Barcelona 2001, p. I.

2 Ibidem, p. 32.

${ }^{3}$ Por otra parte a Zugazagoitia no le dio reparo saber perfectamente que su afirmación coincidía con lo que había declarado Calvo Sotelo en su famoso discurso en las Cortes del 13 de junio de 1936 cuando dirigiéndose hacia los escaños de la izquierda había dicho: "Ahí y allí hay diputados con votos de gentes pertenecientes a la pequeña burguesía y a las profesiones liberales que a estas horas están arrepentidas de haberse equivocado el 16 de febrero al dar sus votos al camino de perdición por donde nos lleva a todos el Frente Popular» (en F. DÍAZ-PLAJA, La preguerra española en sus documentos (19231936), Ediciones GP, Barcelona 1969, p. 445).

4 Sobre la importancia del voto moderado para el Frente Popular véase J. TUSELL, Las elecciones del Frente Popular en España, Editorial Cuadernos para el Diálogo, Madrid 1971, vol. 2, p. 59 y ss. 
una actitud de abstención, de retraimiento, o por lo menos de tibia participación a la defensa de la República del Frente Popular, si esta fuera atacada por un levantamiento militar.

Para que la conspiración pudiese volverse golpe hacía falta que se creara el ambiente social favorable, que creciera el malestar social, sobre todo entre las clases medias. Para el éxito de sus planes los conspiradores necesitaban que en el mismo ejército, cuya oficialidad estaba hecha básicamente de clases medias, crecieran los que les eran favorables o por lo menos los desafectos a la República frentepopulista indiferentes a su destino. El 17 de febrero cuando los conspiradores empezaron a conspirar todo esto no estaba asegurado. Con la situación que se fue creando en los meses sucesivos ellos se fueron envalentonando. Había muchas señales de que el malestar se iba extendiendo y de esto sacaron aliciente.

\section{VISTO BUENO PARA LA VIOLENCIA: GOBIERNOS DÉBILES Y PARTIDISTAS}

Volvamos a lo que escribía Zugazagoitia. Si reparamos en cuan distintos y opuestos eran los dos bandos en el momento de las elecciones, este acercamiento, en tan poco tiempo, de una parte del electorado del Frente Popular al bando contrario no se lo puede achacar a causas superficiales, sino que a motivos muy graves. Uno de los motivos a los que se le suele atribuir la mayor importancia es justamente la gran cantidad de violencia y la constante perturbación del orden público que caracteriza los meses del anteguerra. Pero ¿de qué violencia se trataba y de qué manera pudo favorecer a los conspiradores?

Una parte importante de la historiografía de orientación pro-republicana sostiene que el gran volumen de violencia que se registra en aquel período derivaba en gran medida de los actos terroristas de la derecha dirigidos a provocar reacciones violentas de sus oponentes y a crear un clima de desorden, de inseguridad, de miedo, que deslegitimara el gobierno, incapaz de mantener bajo control la situación, y favoreciera por lo tanto el golpe militar, que la opinión pública asustada acogería como una vuelta al orden y a la tranquilidad. El ejemplo más claro de este planteamiento lo encontramos en la obra más reciente de Rafael Cruz, en la que se puede leer lo siguiente:

El proceso de deslegitimación de la autoridad española fue una decisión estratégica, política de unas organizaciones amenazadas de perder su escaso poder político tras la derrota electoral de febrero y los reiterados agravios posteriores [...]. La creación del miedo constituyó el mecanismo elegido para extender el carácter de amenaza en buena parte de la población y responsabilizar a la autoridad de su

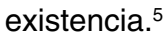

${ }^{5}$ R. CRUZ, En el nombre del pueblo. República, rebelión y guerra en la España de 1936, Siglo XXI, Madrid 2006, p. 191. 
Ahora, aunque es evidente que la derecha política quiso pescar en las aguas turbias de la violencia y que detrás de la violencia falangista hubo también la actividad de la UME, no está probado que hubiese un acuerdo explícito, y por así decirlo una división del trabajo entre derecha política y militares. Más bien sabemos que los militares quisieron prescindir lo más posible de los civiles en sus planes de golpe, reservándoles sólo unos roles auxiliares. No resulta que la violencia falangista - es decir prácticamente toda la violencia de la derecha política- fuese una pieza maestra de la conspiración militar, ni que por otra parte fuera orquestada siguiendo las batutas de Calvo Sotelo o de Gil Robles. El mismo Goicoechea que en un informe a sus «amigos italianos» quiso hacerles creer de estar detrás de los «grupos de acción directa» contrarrevolucionaria no se atrevió a indicar que esa «acción directa» fuese elemento básico de un plan conspirativo concordado con los militares. ${ }^{6}$

Más bien parece que la violencia falangista fue de una simplicidad taurina: atacar al enemigo, darle publicidad a la causa falangista y promover proselitismo a través de esos actos de violencia esperando que fuesen siempre más los que fueran dispuestos a seguir aquel ejemplo. El mismo Zugazagoitia escribía de los falangistas: «Tenían un sentido heroico de su papel y tanto matar como morir se les antojaba cosa natural. Su táctica guardaba una gran analogía con la que en diferentes épocas de su vida colectiva habían puesto en práctica los sindicalistas, movimiento proletario al que los falangistas trataban de atraerse ». ${ }^{7}$

Esto no quita que, como es bien sabido, tanto José Antonio, como, más abiertamente, Calvo Sotelo y, más celadamente, Gil Robles, anhelaran una intervención militar que instaurase un régimen antidemocrático. Y que tarde o temprano, dentro de los límites de sus escasas posibilidades, la favorecieron. Pero esto es muy distinto de la estrategia bien precisa, de los planes de desestabilización a base de violencia que la hipótesis de Cruz indica.

En realidad, lo qua más importa preguntarse es si, al margen de los planes desestabilizadores que pudieran estar detrás de la violencia de derecha, fue esta clase de violencia la que realmente originó ese "gran miedo»" ${ }^{8}$, sobre todo de las cla-

6 En el «rapport» enviado al gobierno italiano por conducto de Ernesto Carpi, Goicoechea escribía: «El ambiente de violencia y la necesidad ineludible de organizarla ha hecho nacer en el seno de los partidos nacionales pequeños grupos de acción directa que por atentados personales, asaltos a edificios, etc., etc., han actuado contra la revolución» (ver todo el informe en I. SAZ, Mussolini contra la Segunda República. Hostilidad, conspiraciones, intervención (1931-1936), Edicions Alfons El Magnánim, Valencia 1986, pp. 167-170). Pero por un lado esto es muy distinto de una acción guiada por propósitos «deslegitimadores», por otro, todo el informe parece caracterizado por una gran exageración de realizaciones, tareas y necesidades de las fuerzas que Goicoechea decía representar, para sacarle dinero -intento fracasado- al gobierno fascista italiano.

7 J. ZUGAZAGOITIA, Guerra y vicisitudes de los españoles, op. cit., p. 33.

8 El tema del «gran miedo» es abordado por Cruz en la p. 190 y ss. Sobre el mismo argumento véanse también mis consideraciones en la ponencia presentada en ocasión del Congreso Internacional de Madrid sobre la guerra civil española de noviembre 2006, cuyo texto en versión italiana —la única de momento publicada - se puede leer en G. RANZATO, La democrazia indifesa: la Spagna repubblicana tra rivoluzione e «non intervento» (1936-1939), en «Ricerche di Storia Politica», n. 3, 2007. 
ses medias, que llevaría a la «deslegitimación» del gobierno, incapaz de aplacarlo. Lo que más importa comprender es si esa «deslegitimación», que en términos políticos concretos significó pérdida del consenso de la izquierda moderada que había votado al Frente Popular, y pérdida de la actitud de aceptación que en un primer momento la derecha moderada había manifestado hacia el nuevo gobierno de la República - con consecuente desviación de esa misma derecha moderada hacia soluciones de fuerza que acabaran con el régimen democrático- fue realmente el producto de una acción derechista encaminada a conseguir ese objetivo.

Lo primero que es importante notar a ese propósito es la total ausencia en las actuaciones de la derecha subversiva eventualmente dirigidas a sembrar desconfianza para con el gobierno del Frente Popular, de ese tipo de atentados que son la punta de lanza del terrorismo desestabilizador, es decir esos atentados indiscriminados en contra de la colectividad de los ciudadanos, que en efecto apuntan a provocar la deslegitimación de un gobierno considerado incapaz de prevenirlos o reprimirlos eficazmente, y que pueden por lo tanto producir en la opinión pública más asustada el deseo de un gobierno fuerte y no democrático. El tipo de atentados que, para hacer un ejemplo más claro y reciente, ha caracterizado, según la interpretación más convincente, la vida pública de la Italia de los años Setenta.

Pero tampoco se puede decir que igual objetivo se pudiese alcanzar con sólo atentar a personalidades de alta significación política o administrativa - como lo fueron, por ejemplo, Jiménez de Asúa o el juez del Supremo Manuel Pedregal—o a oficiales de las fuerzas de policía adictos al régimen, como fue el caso del capitán Faraudo y del teniente Castillo. Porque la posible desconfianza hacia un gobierno juzgado demasiado débil para aplastar esa actividad terrorista no habría abierto camino a un gobierno autoritario afín a la parte política que esa actividad desplegaba, sino, al contrario, a uno más duro en reprimirla y de más marcada caracterización izquierdista.

$\mathrm{Ni}$ los atentados de la derecha, ni las puntuales respuestas y los otros atentados de la izquierda, habrían podido provocar por sí solos la guerra civil. Unicamente el asesinato de Calvo Sotelo contribuyó a que unos cuantos indecisos resolvieran unirse a los golpistas. Pero esto fue solo el empujón final hacia el abismo a cuyo borde el país ya había llegado, y es por otro lado impensable que aquel asesinato estuviera previsto, para legitimar la reacción golpista, en los planes de los conspiradores militares o políticos.

Es más posible que las acciones falangistas fueran aprovechadas por la derecha para atizar la exasperación de los contrarios y provocar una actitud agresiva, una respuesta aun más violenta por parte de estos, que permitiera a los Calvo Sotelo, Gil Robles y su prensa de «incrementar con denuncias dramáticas la sensación de inseguridad ciudadana». ${ }^{9}$ Pero ¿se puede decir realmente que la gran par-

9 J. GIL PECHARROMÁN, Conservadores subversivos. La derecha autoritaria alfonsina (19131936), Eudema, Madrid 1994, p. 271. Pecharromán se refiere al solo Calvo Sotelo. 
te de la violencia de izquierda de este período fue una reacción, aunque a veces desmedida, a la violencia de derecha, y que los líderes derechistas tuvieron necesidad de abultar mucho el monto total de episodios violentos para asustar a la «gente de orden», a los «burgueses» de ambos bandos políticos?

No hay en realidad nada completamente satisfactorio por lo que se refiere a un censo de la violencia de aquellos meses. El trabajo de referencia sobre el tema, es decir el artículo publicado en 1978 por Ramiro Cibrián sobre la violencia política en la España del período que nos ocupa carece de una base documental suficiente como para ser considerado exhaustivo. ${ }^{10} \mathrm{La}$ aportación reciente de Rafael Cruz no sólo está desprovista de indicación de fuentes ${ }^{11}$, sino que aparece, por muchos indicios, un recuento a la baja de los episodios de violencia. ${ }^{12}$ Más convincentes, por lo menos en cuanto al método indicado para acopiar datos, resultan las cifras presentadas en sus trabajos por Juan Blázquez Miguel, que en conjunto rebasan con mucho las denunciadas en las Cortes por los mismos Calvo Sotelo y Gil Robles. ${ }^{13}$ Pero, en cualquier caso, el conjunto de los episodios de violencia y de las víctimas de los mismos, supone que la conflictividad social había llegado muy por arriba de los niveles fisiológicos y que el gobierno era impotente para controlarla. ${ }^{14}$

Si consideramos, por ejemplo, el indicador de la violencia extrema, es decir la que produce víctimas, este juicio no podría variar mucho si aceptáramos el número de 330 indicado en conjunto por Gil Robles, o bien las 273 calculadas por Ce-

10 Cfr. R. CIBRIÁN, Violencia política y crisis democrática: España en 1936, en «Revista de estudios políticos», n. 6, 1978. Los datos básicos en que se fundaba el trabajo habían sido sacados de una recopilación realizada por Edward Malefakis de los sucesos registrados en el diario El Sol y en los periódicos argentinos La Nación y La Prensa. Lo cual implica una infravaloración de los episodios de violencia no sólo por el hecho de que la censura filtraba muchas de las noticias más alarmantes, sino que también porque en cualquier caso la prensa nacional no registraba todos los incidentes que se producían a nivel local.

${ }_{11}$ Es muy singular que en una obra de categoría científica se presenten unos cuantos cuadros estadísticos que el autor declara ser fruto de «elaboración propia» sin que se indiquen las fuentes utilizadas para realizar dicha elaboración.

12 Por ejemplo en el mapa elaborado por Cruz relativo a la distribución geográfica de las víctimas de la violencia política (Cfr. R. CRUZ, En el nombre del pueblo, op. cit., p. 169), se indican 9 en Santander y provincia, donde en cambio según un detallado estudio monográfico se registraron 19 (Cfr. J. SANZ HOYA, De la resistencia a la reacción. Las derechas frente a la Segunda República (Cantabria, 19311936), Universidad de Cantabria, Santander 2006, p. 246). Lo mismo puede decirse por lo que se refiere a Barcelona y provincia donde las víctimas fueron 7 según Cruz y 15 según una tesis doctoral sobre el sindicalismo catalán citada en S. PAYNE, El colapso de la República. Los orígenes de la Guerra Civil (1933-1936), La Esfera de los Libros, Madrid 2005, p. 411.

13 Cfr. J. BLÁZQUEZ MIGUEL, Conflictividad en la España del Frente Popular (febrero-julio de 1936), en «Historia 16», n. 328, 2003, y Idem, Historia militar de la Guerra Civil española, t. 1 Del Frente Popular a la sublevación militar (febrero-julio de 1936), s.e., Madrid 2003. El autor asegura haber sacado sus datos de la consulta de 118 periódicos — sobre todo prensa local-y da alguna muestra de ello. Si bien deje perplejos la posibilidad de que él sólo haya podido realizar sistemáticamente un trabajo de tal envergadura, no hay duda de que esta tarea estaría al alcance de un equipo de investigadores no demasiado numeroso.

14 Sobre el tema véase en particular F. DEL REY REGUILLO, Reflexiones sobre la violencia política en la II República, en M. GUTIERREZ SÁNCHEZ - D. PALACIOS Cerezales (eds.), Conflicto político, democracia y dictadura. Portugal y España en la década de 1930, Centro de Estudios Políticos y Constitucionales, Madrid 2007, p. 76 y ss. 
brián, las 262 de Cruz o las 444 de Blázquez. Porque en cualquier caso, aun admitiendo que, como indica Cruz, la autoría del $43 \%$ de esas muertes fuera atribuible a la fuerza pública y que el $56 \%$ de las víctimas pertenecieran a la izquierda ${ }^{15}$, tan alto número de víctimas mortales, como por otro lado la enorme cantidad de enfrentamientos que a menudo se saldaron «sólo" con heridos y lesionados, muestra claramente la incapacidad del gobierno republicano para mantener el monopolio de la violencia y garantizar el orden público, no obstante fuera evidentemente dispuesto a emplear métodos coercitivos extremos para conseguirlo.

Pero lo que principalmente pudo preocupar la opinión moderada y cambiar más radicalmente su actitud de fondo hacia el gobierno de Frente Popular no fue ni el número de episodios violentos y de víctimas, ni su incapacidad de poner coto a la violencia en general, sino que sobre todo su falta de neutralidad en reprimirla, su falta de voluntad de oponerse a ella en igual medida, viniera de donde viniera.

La falta de neutralidad frente a la violencia de los principales órganos de un Estado democrático siempre ha sido una importante premisa de su hundimiento. Así fue en la Italia de la primera posguerra y en la Alemania de Weimar, donde gran parte de las fuerzas del orden público, de la magistratura, del ejército, colaboraron a la transición de la democracia a la dictadura, garantizando en gran medida la impunidad a la violencia fascista. Y éste pasaje fue relativamente poco traumático, porque la dictadura se presentaba como la mejor garantía de conservación de aquel mismo sistema económico-social que también el Estado democrático quería conservar. En cambio ese mismo hundimiento del sistema democrático se realizó en España a través del inmenso traumatismo de la guerra civil, porque el Estado no neutral no estaba del lado de la conservación, sino más bien del de la revolución. $\mathrm{O}$, mejor dicho, estaba controlado por un gobierno decidido a realizar reformas muy radicales, cuya vinculación estrecha e imprescindible al ala revolucionaria de la coalición le llevaba sin embargo hacia derroteros revolucionarios.

La falta de neutralidad de los gobiernos de Frente Popular en reprimir la violencia de unos y de otros no fue sólo un hecho que se produjo de manera espontánea a medida que tuvo que enfrentarse con los episodios de violencia, sino que respondió también a un planteamiento preciso. De hecho esos gobiernos fueron muy decididos en cortar la actividad de la Falange y lo hicieron a la raíz, poniéndola fuera de la ley, persiguiendo sus bandas armadas y encarcelando su plana mayor con su mismo jefe José Antonio. Es lo que tenían que hacer, ya que se trataba de enemigos del régimen democrático que actuaban fuera de la ley. Pero no hicieron lo mismo con las milicias armadas socialistas y comunistas, que aunque no tuvieran como blanco inmediato de sus acciones el sistema democrático,

15 Cfr. R. CRUZ, En el nombre del pueblo, op. cit., p. 167. Sería de sumo interés que el autor ofreciera un análisis pormenorizado de las circunstancias en que la fuerza pública provocó esas muertes y de la filiación político-social de las víctimas —es bien sabido que las fuerzas del orden produjeron bajas también en las filas de la bandas de derecha-, ya que sólo sobre el conocimiento de estos datos se puede fundar una correcta valoración del fenómeno. 
igualmente actuaban fuera de la ley: con sólo existir —ya que en un régimen democrático no pueden existir cuerpos armados fuera de los del Estado-y con actuar atentados y violencias contra los militantes de la derecha, tanto como respuestas a los de estos que de su propia iniciativa. Y lo peor es que el gobierno y muchos órganos del Estado a los que estaba encomendado el orden público no sólo toleraron la existencia de esas milicias sino que a menudo las protegieron, cuando no las emplearon como fuerzas auxiliares y complementarias de los cuerpos de policía.

La existencia de esas milicias «rojas» ya había creado un grave problema en el origen del Frente Popular, ya que había contribuido a debilitar su ala moderada obligando al Partido Nacional Republicano de Felipe Sánchez Román a quedar fuera de la coalición por haberle negado los partidos que la integraban que en el programa electoral figurase, junto a otros objetivos que aquel partido indicaba, el de la disolución de todas las milicias armadas sin excepción alguna. ${ }^{16}$ Lo cual era imposible en vista de que en el programa propuesto por el Partido Socialista como por otro lado por el comunista- a los demás partidos que iban a formar el Frente Popular había la institución de unas milicias civiles armadas ${ }^{17}$, cuyo núcleo evidentemente habrían de ser las ya existentes milicias juveniles socialistas. ${ }^{18}$ Aunque estas exigencias del Partido Socialista finalmente no tuvieron acogida en el programa, es evidente que Azaña y los demás republicanos no habrían podido, manteniendo en pie la alianza político-electoral, imponerles la supresión de sus milicias.

Por lo tanto no sólo ellas siguieron existiendo tras la victoria del Frente Popular sino que crecieron y multiplicaron sus actuaciones. No sólo para luchar contra las bandas de la Falange - pero ¿no bastaban las fuerzas del orden del Estado para desarticular esa pandilla de delincuentes políticos? - sino que también en los pueblos y en el campo para imponer a autoridades locales, propietarios y empresarios, exigencias «proletarias» legales e ilegales.

En un discurso pronunciado en las Cortes a primeros de mayo Calvo Sotelo denunciaba con mucho vigor las acciones de esas milicias «rojas» afirmando que el Estado había

degradado su propia jerarquía insustituible y suprema, consintiendo la incrustación apendicular de organismos milicianos marxistas que suplen a las fuerzas del Es-

16 Véanse a este propósito las declaraciones hechas por el mismo Sánchez Román durante una asamblea de su partido en El Sol, 10 de marzo de 1936.

17 En las bases programáticas presentadas por los socialistas a los demás partidos se indicaba la «creación de una milicia armada, integrada por republicanos y socialistas» y en las de los comunistas la "creación de una milicia popular armada formada por obreros y campesinos". (Cfr. F. LARGO CABALLERO, Escritos de la república. Notas históricas de la guerra en España (1917-1940), Editorial Pablo Iglesias, Madrid 1985, pp. 259 y 275.

18 Sobre las milicias socialistas, su origen y su papel en la revolución de octubre véase J.C. GIBAJA VELÁZQUEZ, La tradición improvisada. El socialismo y la milicia, en «Historia contemporánea», n. 11, 1994. 
tado, que nunca debieran prestarse a tales sustituciones.[...] ¿Cómo y por qué hay ciudadanos pertenecientes a una determinada fracción política que, invistiéndose de hecho de una autoridad que no les corresponde, cachean, registran, detienen y ejercen facultades policíacas, amparados unas veces y suplantando otras a los gobernadores civiles? ${ }^{19}$

Y más adelante, en el curso del debate, añadía:

Sostengo y repito que actualmente al lado de las autoridades públicas y oficiales del Estado constituido actúan erigidas en autoridad facciosa, aunque cuando no lo parezcan, elementos sociales que poseen armas, no sólo cortas, sino largas, que las esgrimen y exhiben, que con ellas al hombro o en el bolsillo realizan funciones policíacas y que vejan, por consiguiente, al resto de los ciudadanos españoles. Nosotros no recusamos las actuaciones del Poder público cuando se fundan en una ley[...]; de lo que tenemos que protestar airadamente es de que estos particulares, pertenecientes a agrupaciones o organizaciones de tipo social, asuman funciones estatales. ${ }^{20}$

En este caso también se podría considerar que Calvo sólo quisiera acrecer con sus denuncias dramáticas la sensación de inseguridad ciudadana. Pero la sustancial realidad de lo que el denunciaba queda confirmada en las palabras con que Casares Quiroga, entonces todavía ministro de Gobernación, contestaba al líder monárquico - sin negar la existencia de esas milicias y sin refutar siquiera las acusaciones que se les dirigían- que le exigía el desarme de todas las formaciones armadas extralegales, fuera cual fuera su filiación política.

¡Calma, Sr. Calvo Sotelo! -le decía el ministro-Son las derechas las que me preocupan en este momento, porque, a pesar del Estado subalterno que S.S. inventa, a mí no me preocupa la revolución social [...]; en los momentos duros he encontrado el respaldar de unos hombres, de una opinión y de un proletariado que saben ayudar a salir del trance [...], ante todo, procedo al desarme de aquellos elementos de peligrosidad más inmediata. Esto no quiere decir, ni remotamente, que no piense y actúe para el desarme de los demás [...pero] ¡han caído nuevamente gentes de nuestros partidos! ¡Ha habido, otra vez, coches, coches con gente pistolera, que no era precisamente proletaria, que ha vertido, otra vez, la sangre de nuestros partidos del Frente Popular! Contra eso iré constantemente, antes que nada y por encima de todo. ${ }^{21}$

Era la anticipación de una línea de conducta que luego Casares Quiroga habría rotundamente expresado en la presentación de su gobierno con la famosa frase: «Contra el Fascismo el Gobierno es beligerante». Una afirmación que, contrariamente a lo que muchos -y no sólo en la derecha extrema- le reprocharon, era perfectamente lícita y casi obvia, porque todo gobierno democrático está en guerra contra cualquier organización que se propone hundir, no sólo con palabras sino

19 Diario de Sesiones de las Cortes (DSC), 6 de mayo de 1936, n. 25, p. 31.

20 Ibidem, p. 35.

21 Ibidem, p. 33. 
que con hechos, el mismo sistema democrático. ${ }^{22}$ Lo que en cambio tuvo que preocupar mucho a los demócratas moderados era que el ministro no expresara igual beligerancia contra sus aliados de la extrema izquierda que se proponían abiertamente $-\mathrm{y}$ ya actuaban con sus milicias en esa dirección- de acabar no sólo con la amenaza fascista sino que también con el vigente sistema económico social de la democracia liberal. Esto a Casares no le inquietaba, a pesar de que, como es sabido, los caballeristas anunciaran cotidianamente este propósito y en la sesión de Cortes del 6 de mayo uno de ellos, el secretario del sindicato campesino Ricardo Zabalza, dirigiéndose al diputado de la derecha Bermúdez Cañete que había denunciado las coacciones a las que en la provincia de Córdoba estaban sometidos también los pequeños propietarios por parte de las «milicias rojas», dijera claramente:

Esas otras milicias rojas que llenan de espanto a SS.SS., esas otras milicias rojas, que no son milicias hechas para asaltar ni robar ni para matar obreros, como la morisma que trajisteis vosotros - [la alusión es al octubre 1934]-, sino que son milicias al servicio de la República, dispuestas a defender estas situaciones para, cuando las conspiraciones que estos señores están urdiendo en la sombra den resultados, señores del Gobierno, salir a la defensa de la República para hacer morder el polvo de la derrota a esos señores y lograr que en España haya lo que debe haber. ${ }^{23}$

Estas palabras tan proféticas - y quizás programáticas - sobre el desarrollo futuro de los acontecimientos, debieron de intranquilizar mucho, siendo transparente lo que Zabalza entendía con «lo que debe haber», no sólo a los «señores» de la tierra, sino también a todos los que temían la revolución y que en aquellos días podían ver, sobre todo en las ciudades y particularmente en la capital, que esas milicias a las que los Zabalzas confiaban tareas de tal calibre se desarrollaban al amparo de las fuerzas públicas del Estado y, se podría decir, en intimidad con ellas.

Sobre este punto tenemos el testimonio muy fidedigno de Manuel Tagüeña, uno de los más altos mandos comunistas del ejército republicano que, a pesar de su sucesivo alejamiento del partido, no llegó nunca a renegar de su militancia durante la guerra civil. Tagüeña, que en la primavera de 1936 era en Madrid miembro de las MAOC (Milicias Antifascistas Obreras y Campesinas), creadas por el PCE,

22 La frase completa pronunciada por Casares era: «Cuando se trata del fascismo, cuando se trata de implantar en España un sistema que va contra la República democrática y contra todas aquellas conquistas que hemos realizado en compañía del proletariado, jah!, yo no sé permanecer al margen de esas luchas y os manifiesto, Sres. del Frente Popular, que contra el Fascismo el Gobierno es beligerante» (DSC, 19 de mayo de 1936, n. 29, p. 6). Lo cual indica, a pesar de la ambigua alusión a las «conquistas de proletariado", que él se refería al fascismo stricto sensu. Es muy revelador del clima de guerra civil que ya caracterizaba el país el hecho de que la interpretación casi unánime de su afirmación fue que él se declaraba en guerra contra todos los adversarios del Frente Popular, es decir, como muchos dijeron, contra «la mitad del país».

${ }^{23}$ DSC, 5 de mayo de 1936, n. 24, p. 24. 
así describe en sus memorias el cuadro de las relaciones entre cuerpos armados del Estado y milicias de izquierdas:

Reclutados durante la República entre jóvenes obreros y de la clase media, los guardias de asalto en su mayoría, simpatizaban con el Frente Popular[...]. También la Guardia Civil estaba, en parte, neutralizada bajo el mando de un republicano, el general Pozas[...]. [Los de las MAOC] teníamos sólo tres compañías, con unos trescientos hombres en total, la mayoría muy jóvenes. Contábamos desde luego con la benevolencia de las autoridades, incluso varios recibimos licencia de uso de armas. Una noche, guardias civiles detuvieron en los alrededores de Madrid a varios compañeros nuestros [...]. Una simple llamada telefónica que hizo Ordóñez al ayudante del general Pozas, consiguió no sólo la libertad inmediata de los arrestados, sino que les devolvieron sus armas. ${ }^{24}$

Si tales eran las relaciones entre una parte importante de las autoridades de policía y las milicias comunistas - muy activas pero limitadas en número de militantes- más estrechas lo eran con las más numerosas milicias socialistas, que junto a las primeras desfilaron en muchos actos públicos -Primero de Mayo, creación de la JSU, mítines y celebraciones en distintas ciudades- y con ellas compartieron los instructores, todos procedentes de la oficialidad de la fuerza pública. ${ }^{25}$ Hay que preguntarse entonces qué imagen de neutralidad podía dar un gobierno que, a pesar de tener un buen control de las fuerzas regulares de policía, permitía que existieran milicias armadas de izquierdas, que no ocultaban su vocación revolucionaria y protagonizaban una lucha diaria con sus enemigos políticos entremezclándose con los órganos oficiales de la fuerza pública.

La penetración de los hombres de la extrema izquierda en los cuerpos de policía apareció con la mayor evidencia en ocasión del asesinato de Calvo Sotelo. Está de sobras subrayar la gravedad del hecho de que aquel asesinato se cometiera por hombres de la Guardia de Asalto y de la Guardia Civil a los que estaba encomendado el respeto de la ley, militantes en el Partido Socialista y muy bien conocidos por su líderes, que a menudo los empleaban como guardaespaldas. Pero quizás el aspecto de mayor gravedad que aquel acontecimiento ponía de manifiesto es el hecho de que aquella descabellada actuación salía de un ambiente de mezcolanza de funciones entre hombres de la fuerza publica y hombres de los partidos obreros y de sus milicias. Un testimonio irrebatible de esto es todavía Tagüeña, que recordaba lo que pasó, después de que mataron al teniente Castillo, en el cuartel de Pontejos, donde los hombres de las milicias se mezclaron a los uniformados para preparar una respuesta a ese asesinato y donde el mismo Tagüeña colaboró a redactar una lista de detenciones que había que realizar. ${ }^{26}$

24 M. TAGÜEÑA, Testimonio de dos guerras, Planeta, Barcelona 2005 (México 1973), p. 94. Sobre las MAOC ver J.A. BLANCO RODRÍGUEZ, Las MAOC y la tesis insurreccional del PCE, en "Historia Contemporánea», n. 11, 1994.

25 Sobre este punto véase Ibidem, pp. 96-97.

26 Cfr. Ibidem pp. 99-100. 
Al margen de las consecuencias de enorme gravedad que el asesinato de Calvo Sotelo por sí mismo conllevaba, quizás su efecto más desestabilizador para la República estribó en el hecho de que la opinión pública moderada, tanto de derechas que de izquierdas, vio en él el punto de no retorno de un proceso de identificación progresiva y siempre más evidente entre fuerza pública del Estado y milicias extralegales, no simplemente afectas al Frente Popular, sino que a la izquierda extrema, revolucionaria, caballerista y comunista. ${ }^{27}$ Es evidente que esta realidad no podía que despertar los más grandes temores en los moderados de derechas que ya veían en acto una política del gobierno y una práctica social que a sus ojos ya lindaban la revolución, que ya oían no sólo las voces que la anunciaban y exhortaban a prepararla de los líderes de izquierda - como el Largo Caballero del discurso de Oviedo en que incitaba a «acelerar la organización del Ejército rojo»28_ sino que también de muchos hombres de la calle. Pero también los moderados de izquierdas, y sobre todo los que entre ellos tuvieran algunos lícitos intereses materiales que defender, como podría ser una empresa, un comercio, un taller, un campo dado en arriendo, en breve todos los moderados anticomunistas de izquierdas, debían a su vez traer los más obscuros presagios de este progresivo control que la extrema izquierda iba ejerciendo sobre las fuerzas de policía. Y de estos presagios, de estas preocupaciones derivaron, si no la decisión de apoyar el golpe, sin duda una pasividad, una imposibilidad de defender la República con la misma decisión que si hubiesen tenido la seguridad de que la que iban a defender era y quedaría realmente una república democrática.

Pero para entender bien el peso de la violencia en crear las condiciones de la guerra civil, debemos valorar no sólo los hechos sino que también apreciar el planteamiento, la actitud de fondo del Frente Popular, y sobre todo de sus mayores representantes, con respecto a la violencia. Esa actitud fue básicamente de gran indulgencia y preliminarmente exculpatoria hacia la violencia de izquierdas, entendida sin más como espontánea violencia popular. Esta violencia, que se manifestó ya como inmediata secuela de la victoria electoral, tuvo casi coralmente, se podría decir, por parte de la izquierda política, este tipo de justificación: después de la represión que siguió a la revolución de octubre y la persecución que durante casi dos años debieron padecer obreros y campesinos, más o menos complicados con aquel octubre, es comprensible que las masas se hayan desbordado.

27 A pesar de que no existieran planes revolucionarios comunistas es suficiente consultar la colección de Mundo Obrero de estos meses para darse cuenta de que el PCE más que en aplicar una política de Frente Popular a la francesa — defensa de la República «burguesa» contra el fascismo- estaba empeñado en una carrera extremista en competición/consonancia con los caballeristas. No tenía mucho que ver, por ejemplo, con aquella política de Frente Popular, el exordio del discurso pronunciado en julio por José Díaz en Oviedo, en el que decía: «Para un dirigente de un partido obrero no puede haber mayor satisfacción que hablar, que dirigir la palabra por primera vez en el corazón del levantamiento armado de Octubre; hablar al pueblo que ha dado un ejemplo que ha salido de las fronteras de España para tener su repercusión en todo el mundo capitalista» (Mundo Obrero, 6 de julio de 1936).

${ }^{28}$ En su discurso Caballero decía a renglón seguido: «Las finalidades concretas de este ejército serán: sostener la guerra civil que desencadenará la instauración de la dictadura del proletariado» (Claridad, 15 de junio de 1936). 
Ya el mismo Azaña en su primer discurso parlamentario decía: « ¿Es que se puede pedir a las muchedumbres irritadas o maltratadas, a las muchedumbres hambrientas durante dos años, a las muchedumbres saliendo del penal, que tengan la virtud que otros tenemos de que no transparenten en nuestra conducta los agravios de que guardamos exquisita memoria?». ${ }^{29}$ Durante el debate que siguió al discurso con que Azaña había presentado su gobierno, el socialista, Rodolfo Llopis, futuro subsecretario de la presidencia del gobierno Caballero durante la guerra, elevaba este planteamiento a principio general:

Todo lo que ha ocurrido en España el 16 de Febrero y después del 16 de Febrero, no se puede enjuiciar más que en función de lo que ha ocurrido en España antes del 16 de Febrero[...]. No hay ningún elemento de izquierda en España que no haya sentido en su cuerpo o en su espíritu las huellas de los dos años que hemos dado en llamar «bienio negro». Sabían, pues, perfectamente los elementos de derecha que existía una irritabilidad justificadísima en las masas populares españolas, que estaban dispuestas a responder a la primera provocación. ${ }^{30}$

Durante todo aquel debate las denuncias por parte de los representantes de la derecha fueron constantemente interrumpidas por diputados de la izquierda que no negaban los hechos denunciados sino que los presentaban como respuestas a provocaciones ${ }^{31}$, o a pasados agravios padecidos por el pueblo, sobre todo en Asturias. ${ }^{32}$ Y el mismo Azaña, decía en su réplica: «Después de las opresiones y de las persecuciones y del hambre pasada por el pueblo español en muchas provincias a consecuencia de una política, es muy difícil impedir, no digo corregir, que ésa es la obligación del Gobierno[...] explosiones violentas»..33

Esto quería decir que, si no se justificaba, se comprendía, y se comprendía mucho el espíritu de venganza que animaba a las masas. Y se comprendía porque este mismo espíritu de venganza animaba en parte a los hombres de la mayoría y del gobierno. En primer lugar al mismo Azaña, así como lo manifestaba cuando, dirigiéndose a los representantes de la oposición que se quejaban de la violencia, les recordaba que ellos mismos habían amenazado estragos durante la campaña electoral, y concluía diciendo: «¿No queríais violencia, no os molestaban las instituciones sociales de la República? Pues tomad violencia. Ateneos a las consecuencias». ${ }^{34}$ Josep Pla, a pesar de sus prejuicios derechistas, no estaba lejos de la

29 Véase en El Liberal del 4 de abril de 1936.

30 DSC, 15 de abril de 1936, n. 17, p. 30.

31 Así lo notaba en su intervención Joan Ventosa diciendo: «Cuando se han lanzado aquí acusaciones, cuando se han dado, por el señor Calvo Sotelo sobre todo, cifras concretas de los ataques cometidos, yo he oído interrupciones y voces, ninguna de las cuales negaba los hechos - los hechos son innegables, existen, los conocemos todos-; lo que decían es que, frente a estos hechos que podían ser imputables a elementos extremistas de izquierda, había otros hechos que podían ser imputables a elementos de derecha o que eran efectos de provocaciones de elementos de derecha" (Ibidem, p. 26).

${ }^{32}$ Así, por ejemplo, Dolores Ibarruri interrumpía a Calvo Sotelo diciéndole: «ld a decir esas cosas en Asturias», con Margarita Nelken que le hacía eco diciendo: «Vamos a traer aquí a todos los que han quedado inútiles en Asturias» (Ibidem, p. 15).

${ }_{33}$ DSC, 16 de abril de 1936, n. 18, p. 11.

34 Ibidem, p. 7. 
verdad cuando, comentando esas intervenciones de Azaña en aquel debate, escribía: «Es la pura y simple teorización de la política del desquite, la teorización de la Guerra Civil hecha por un resentido. Todo lo que está sucediendo es obra del desquite. Todo lo que está sucediendo es la consecuencia lógica y natural de una provocación previa de las derechas». ${ }^{35}$

\section{VIOLENCIA, CONFLICTOS SOCIALES Y ACCIÓN DE GOBIERNO}

Había por otra parte una consciente negación de la realidad en los representantes del Frente Popular cuando identificaban toda la violencia de izquierdas con un espontáneo desbordamiento de las masas. En realidad muchas de las violencias que se cometieron no tuvieron nada que ver con las respuestas a las provocaciones fascistas o con súbitos furores populares. Tuvieron que ver con las luchas sociales y no podemos por lo tanto valorarlas con independencia de la valoración relativa a aquellas luchas y a las perspectivas que abrían.

Una gran parte de la violencia ligada a los conflictos sociales se manifestó en el campo y tuvo que ver con la propiedad de la tierra, con los arriendos, con la ocupación, con las condiciones de trabajo, con los salarios. En el debate que en las Cortes siguió al discurso con que Casares Quiroga había presentado su gobierno, Calvo Sotelo describía así la situación del campo:

Una gran parte de España, unos cuantos millones de españoles viven sojuzgados por unos déspotas rurales, monterillas de aldea, que cachean, registran, multan, se incautan de fincas, parcelan y dividen la tierra, embargan piaras de ganado, centenares y millares de reses [...], individuos que realizan todas clases de funciones gubernativas, judiciales y extrajudiciales, con total desprecio de la ley, desacatando a veces las órdenes de la autoridad superior, pisoteando los Códigos vigentes y no reconociendo otro fuero que el del Frente Popular. ${ }^{36}$

¿Visión exagerada y partidista? Sin duda había en ese cuadro una generalización arbitraria. Pero el mismo Casares había declarado en su discurso que el gobierno no podía admitir «que para las conquistas que crean precisas para sus reivindicaciones de clases las masas proletarias o republicanas impongan [...]incautaciones que no pueden ser permitidas por el Gobierno» $y$ «actos de violencia que sean un trágala al Gobierno, o una coacción en todo caso», añadiendo una advertencia — «El Gobierno, por dignidad, no puede trabajar en esas condiciones ${ }^{37}$ - que implicaba una gran extensión del fenómeno.

Por otra parte encontramos una sustancial confirmación de los desórdenes que Calvo denunciaba en unas cuantas obras historiográficas que no se pueden sos-

35 J. PLA, Historia de la Segunda República Española, vol. IV, Destino, Barcelona 1940, p. 404.

${ }^{36}$ DSC, del 19 de mayo de 1936, n. 29, p. 18.

37 Ibidem, pp. 7-8. 
pechar de simpatías derechistas. Una de ellas, por ejemplo, dibuja así el panorama que se creó en el campo en los meses que siguen la victoria del Frente Popular:

Tras precipitar una nueva oleada de destituciones de ayuntamientos y diputaciones y reponer a los alcaldes y concejales de elección popular depuestos en el bienio anterior, las fuerzas de izquierda comenzaron a intervenir en asuntos gubernativos, judiciales y laborales, controlando el orden público a través de milicias, efectuando detenciones espontáneas, imponiendo multas y penas de encarcelamientos a los patronos que no aceptaban los repartos y los salarios impuestos por las Casas del Pueblo, estableciendo controles en las carreteras, destituyendo a jueces de paz hostiles o conformando Jurados Mixtos de circunstancias, que se vieron frecuentemente desbordados por las reclamaciones salariales. ${ }^{38}$

Toda esta actividad implicaba en muchas áreas un ataque generalizado a los propietarios de tierra que muy a menudo no ahorraba a los pequeños propietarios, ya que ellos, según ha escrito Edward Malefakis, «vivían en constante temor de convertirse en víctimas de la agresión de los obreros a medida que la definición de «burgués» y «fascista» se ampliaba hasta incluir a cualquier propietario por pequeño que fuese». ${ }^{39}$

Las Actas de las Cortes están llenas de las protestas de diputados de las derechas que denunciaban los atropellos que padecían medianos o hasta pequeños propietarios cuyas fincas eran ocupadas por braceros asistidos por el sindicato socialista sin respetar los límites impuestos por la misma ley de Reforma Agraria, o de modestos yunteros y arrendatarios expulsados de las tierras que cultivaban, por católicos o en cualquier caso contrarios al Frente Popular. ${ }^{40}$ Asimismo esos diputados protestaban en nombre de aquellos propietarios y empresarios por la imposición a que a menudo estaban sometidos de pagar salarios muy altos o de emplear braceros en número superior a lo necesario y a lo que podía soportar su presupuesto.

Es evidente que estos representantes de la derecha encubrían bajo los intereses dañados de los medianos y pequeños propietarios o arrendatarios los intereses de los grandes terratenientes que más les importaban. Pero esto no quita que también esos más pequeños intereses fueran atropellados. La preocupación, por ejemplo, de que el hecho de imponer unos salarios exorbitantes, en el campo como por otra parte en toda clase de empresas, llevara a la quiebra del sistema

38 E. GONZÁLEZ CALLEJA, La dialéctica de las pistolas. La violencia y la fragmentación del poder político durante la Segunda República, en J. MUÑOZ, J.L. LEDESMA, J. RODRIGO (Coods.), Cultura y políticas de la violencia. España siglo XX, Siete mares, Madrid 2005, p.137.

39 E. MALEFAKIS, Reforma agraria y revolución campesina en la España del siglo XX, Ariel, Barcelona 1971 (ed. or.1970), pp. 438-439.

40 Ya entrado el mes de marzo, el director del IRA, Adolfo Vázquez Humasqué, anunciaba en una entrevista desde Badajoz la intención de asentar unos 40.000 yunteros poniendo, no casualmente, esas condiciones a la concesión: «No roturar tierra impropia para el cultivo y no quitarla a los yunteros o modestos arrendatarios de la tierra que la laboren en la actualidad, aunque sean de la acera de enfrente: que en el sentido de hermandad tutelar hemos de distinguirnos las izquierdas de los que no lo son» ( $P$ Olítica, 13 de marzo de 1936). 
económico la expresaba con mucha claridad el mismo Prieto cuando a finales de mayo hablando en Bilbao decía:

Las aspiraciones proletarias dentro del régimen capitalista encuentran forzosamente un tope: la capacidad de la economía capitalista. Cuando las aspiraciones del proletariado en la consecución de mejoras desbordan la capacidad de la economía capitalista, esas aspiraciones están condenadas al fracaso, y en vez de servir para aumentar la capacidad de compra del obrero y acrecer su bienestar producen la contracción y con la contracción a veces el colapso [...] ¿Que la causa de estos trabajadores es justa? Justísima. Mas la justicia no puede ser el regulador único de las aspiraciones obreras mientras subsista el actual sistema [...]. Si originamos en los productos españoles una carestía en su coste que los aleje de campo de la competencia, el resultado será profundamente dañoso, no sólo para la economía capitalista, que esto a un socialista le podría interesar poco, sino por los propios obreros, que, en ansias de justicia, sólo realizable dentro del socialismo integral, desbordasen las posibilidades de la economía capitalista, dentro de cuyo régimen estamos viviendo. ${ }^{41}$

Estas palabras, unas de las pocas tan claramente $-\mathrm{y}$ tan atrevidamente en aquel entonces- reformistas pronunciadas en esos meses por un líder socialista, cayeron en saco roto. El resultado fue que en el campo, «sin miedo a pecar de exagerados se puede estimar que los costes de la mano de obra se triplicaron durante los primeros meses de gobierno del Frente Popular» ${ }^{42}$ Se trataba, según ha escrito Manuel Tuñón de Lara, de unas condiciones que «aumentaban los costes de producción a unos niveles insoportables para los propietarios de tipo medio» -y aún más, se podría añadir, para los pequeños que empleaban mano de obra asalariada - y contribuía mucho a determinar el «estado de ánimo exasperado de los propietarios". ${ }^{43}$ Sobre todo porque los altos salarios se consiguieron por los obreros agrícolas mucho más por las malas que por las buenas.

Los costes de producción — ha escrito Malefakis - se vieron elevados de forma significativa por el creciente mal uso del principio de alojamiento, tanto por parte de los propios trabajadores que en bandas invadían las fincas y forzaban a los propietarios a garantizarles un empleo, como por parte de los atormentados funcionarios locales, que intentaban aquietar la agitación campesina asignando a cada explotación muchos más trabajadores de los que necesitaban. ${ }^{44}$

El choque de intereses entre propietarios, arrendatarios y asalariados - como por otro lado al interior de estos mismos, pretendiendo socialistas, anarquistas y católicos excluir del trabajo los unos a los otros- estuvo a la raíz de todas las violencias que se cometieron en el campo en este período. Violencias de los guardias de los grandes terratenientes que defendían las propiedades de sus amos, vio-

41 El Liberal, 26 de mayo de 1936.

42 E. MALEFAKIS, Reforma agraria y revolución campesina, op. cit., p. 428.

${ }_{43}$ M. TUÑÓN DE LARA, Tres claves de la Segunda República, La cuestión agraria, los aparatos del Estado, Frente Popular, Alianza Editorial, Madrid 1985, p..182.

44 E. MALEFAKIS, Reforma agraria y revolución campesina, op. cit., p. 428. 
lencias de la Guardia Civil que hacía lo mismo - a veces con mucha brutalidad como en el episodio de Yeste- pero que en cualquier caso tenía la obligación de hacer respetar la legalidad 45 ; y por otro lado violencia de los campesinos, guiados por hombres o milicias del sindicato o de los ayuntamientos del Frente Popular, para imponer su voluntad a los propietarios.

El gobierno no llegó a acabar con estas violencias, como por otra parte no pudo acabar con el movimiento huelguístico - y con los episodios de violencia que le acompañaron- que se desató sin parar en las ciudades, en primer lugar porque las masas, los sindicatos, socialistas y anarquistas, que realizaban todo esto, se desentendieron completamente del gobierno y éste no pudo reprimirlas. No lo pudo principalmente porque el gobierno de Frente Popular tenía como básico soporte parlamentario el Partido Socialista, de hecho controlado por los caballeristas, que alentaba y protagonizaba ese movimiento agresivo, cuyo blanco no eran sólo los intereses de los grandes terratenientes y de las grandes empresas, sino que todo el sistema económico político basado en la propiedad y la empresa, es decir el sistema capitalista y el régimen de democracia liberal que le era consustancial.

Tenemos muchas indicaciones de que este objetivo, cuyo alcance era anunciado muy próximo por los caballeristas, fue por estos perseguido con alimentar abiertamente los conflictos, rindiendo la vida imposible al gobierno republicano. Zugazagoitia escribe que a Caballero y sus allegados la creciente tensión social «lejos de producirles la menor inquietud, provocaba en ellos un secreto contentamiento, en cuanto las huelgas, los altercados y los encontronazos sangrientos representaban el fracaso gubernamental». ${ }^{46} \mathrm{Un}$ fracaso deseable e inevitable, porque a «los problemas agudamente planteados en España», decía el «Lenin español» en junio hablando en Asturias, «sólo el proletariado podrá hallarles solución desde el Poder y mediante una transitoria dictadura de clase [...]. Otra colaboración republicano-socialista, si no transforma radicalmente los fundamentos económicosjurídicos de la sociedad capitalista, convirtiendo la propiedad privada en social o colectiva $-\mathrm{y}$ a ello se opondrían, como es lógico, los republicanos- colmaría la desilusión del proletariado revolucionario»». ${ }^{47}$

En realidad también a muchos republicanos, aunque no llegaran a hablar de dictadura del proletariado, el entusiasmo de la victoria electoral o quizás la competencia con los socialistas, les llevaron a hacer declaraciones y a veces a actuar de forma tal que aparecieron tener unos objetivos de transformación del sistema socio-económico y del mismo régimen político no muy lejanos de los de los socia-

45 Sólo desde una perspectiva filorevolucionaria se puede considerar cualquier intervención de la Guardia Civil en aquellos meses desprovista de legitimidad y dirigida a favorecer los intereses patronales al margen de lo que dictara la ley. Sobre las responsabilidades de la fuerza pública en los episodios de violencia de este período véase en particular F. DEL REY REGUILLO, Reflexiones sobre la violencia política en la II República, op. cit., pp. 78-79.

46 J. ZUGAZAGOITIA, Guerra y vicisitudes de los españoles, op. cit., p. 31.

47 Claridad, 15 de junio de 1936. 
listas. Ya en el mes de marzo Manuel Azaña —mucho más preocupado de lo que aparentaba en público- hacía alusión a estos inusitados extremismos de algunos de sus correligionarios cuando a su cuñado Cipriano de Rivas le escribía alarmado:

Ahora, vamos cuesta abajo, por la anarquía persistente de algunas provincias, por la taimada deslealtad de la política socialista en muchas partes, por las brutalidades de unos y otros, por la incapacidad de las autoridades, por los disparates que el «Frente Popular» está haciendo en casi todos los pueblos, por los despropósitos que empiezan a decir algunos diputados republicanos de la mayoría. No sé, en esta fecha, cómo vamos a dominar esto. ${ }^{48}$

Quizás el ejemplo más impresionante de esos «despropósitos» lo daría el diputado de Unión Republicana Jerónimo Gomáriz cuando en el siguiente mes de abril hizo en las Cortes unas declaraciones que por su inoportunidad le merecieron una interrupción hasta de la Pasionaria. Durante una de las primeras sesiones dedicadas a la convalidación de las actas electorales, Gomáriz iniciaba su discurso diciendo: «Sres. Diputados, mientras vivamos en un régimen parlamentario - que yo declaro que lo siento- mientras vivamos en él...». A la lbárruri que le interrumpió diciendo: «Yo no lo siento», le contestaba irónico: «Su Señoria no lo siente, iqué le vamos a hacer! ».49

Podría parecer un pequeño episodio sin importancia y en realidad no lo es. Un representante destacado de un partido republicano cuyo ideario era declaradamente liberal y democrático, en plenas Cortes, en el mismo templo, podríamos decir, del régimen parlamentario, en el cual tenía la palabra exactamente en aplicación de las reglas fundamentales de ese régimen, y que además, por ostentar el cargo de secretario de la Comisión de Actas, tenía encomendada la responsabilidad de velar por el respeto de las más básicas de aquellas reglas, declara abiertamente que él lamenta vivir en un régimen parlamentario. Su afirmación es tan enorme que la misma Pasionaria quiere contradecirle - pero es la única voz que se levanta, nadie más se escandaliza y todo termina allí- porque callar hubiera sido un mentís demasiado evidente de la política comunista de Frente Popular.

Pero cabe sobre todo preguntarse en qué estaba pensando Jerónimo Gomáriz cuando decía que lamentaba vivir en un régimen parlamentario y cual régimen hubiese preferido al parlamentario. No hay duda de que no pensaba en una dictadura militar o fascista, sino en un régimen de carácter opuesto, un régimen de tipo socialista en el que sólo podía existir un parlamento casi completamente desprovisto de poderes. Y lo que es más indicativo del clima político de aquellas Cortes es que el episodio pasó casi desapercibido, sin que nadie de sus correligionarios, ni en las Cortes, ni — que conste- fuera de allí, corrigiera al diputado alicantino y le invitara a rectificar.

${ }^{48}$ C. DE RIVAS CHERIF, Retrato de un desconocido, Ediciones Grijalbo, Barcelona 1982, pp. 66768. La carta está fechada 17 de marzo.

49 DSC, 2 de abril de 1936, n. 2, p. 16. 
Es este sólo un ejemplo, aunque quizás el más extremo, de la carrera que muchos representantes del republicanismo emprendieron hacia una radicalización de su orientación política —quizás para secundar el movimiento de las masas y así controlarlo— nada más ganadas las elecciones. Una carrera que les llevó en seguida muy lejos del programa moderado del Frente Popular que les había permitido ganar las elecciones atrayendo también una parte no desdeñable del electorado moderado.

Esta corriente radical-jacobina no tardó a llevarse, aunque con menor ímpetu, al mismo Azaña. A los pocos días de ser nombrado Presidente del Consejo, durante un banquete con sus correligionarios de la Izquierda Republicana decía:

Y ahora tengo que confesaros un secreto. El programa del Bloque Popular es nada más que una parte del programa de Izquierda Republicana, y no la más importante. En cuanto nos desembaracemos del compromiso de cumplir este programa, cuando lo hayamos llevado a la práctica, tendremos que cumplir el nuestro, y lo cumpliremos también íntegramente. Os aseguro que nosotros vamos más allá de lo que marca el programa del Bloque Popular, y hemos de llegar hasta el final, porque consideramos que eso es lo que necesita el país. ${ }^{50}$

Por impreciso que quedara este «programa secreto", no puede caber duda de que los electores moderados del Frente Popular, leyendo estas palabras en El $\mathrm{Li}$ beral de Madrid se sintieron algo defraudados, sabiendo de la existencia de este segundo programa y seguramente algo inquietos sobre su contenido. También en este caso se podría opinar que se trata sólo de un fragmento de un discurso de Azaña que por la ocasión en que fue pronunciado se puede considerar sin importancia. Y sin embargo es un ejemplo revelador de una muy precoz actitud de todos los republicanos a no considerarse en absoluto obligados a limitarse a realizar el programa sobre cuya base habían obtenido el voto de los electores, sino autorizados a ir en seguida «más allá» como decía Azaña, y a veces mucho más allá.

Quizás el que de ese programa se alejó más fue el ministro de Agricultura Mariano Ruiz-Funes, que por otra parte durante su recorrido contó siempre con la aprobación de sus correligionarios. En materia agraria el pacto electoral del Frente Popular era tan discreto que a la Reforma Agraria ni se la nombraba y en él sólo se decía que los partidos que lo habían suscrito, en caso de llevarse el triunfo electoral, llevarían «a cabo una política de asentamientos de familias campesinas, dotándolas de los auxilios técnicos y financieros precisos", sin que siquiera se explicara sobre qué tierras se las asentarían. Más amplio era el apartado dedicado a los arrendatarios a los que se reservaban muchas ventajas entre las que destacaban «la estabilidad en la tierra; la modicidad de la renta» y la consolidación "en la propiedad, previa liquidación, a los arrendatarios antiguos y pequeños». ${ }^{51}$

50 El Liberal, 3 de marzo de 1936.

51 El texto del programa considerado es el que está reproducido en F. LARGO CABALLERO, Escritos de la república, pp. 288-295. 
Pero muy pronto los electores del Frente Popular que fueran pequeños y medianos propietarios que no cultivaban directamente su tierra - y había miles en las clases medias- vieron con creciente alarma que en algunas provincias, sobre todo de Extremadura y Castilla, había un movimiento campesino que ocupaba tierras sin preocuparse mucho de su extensión y amenazaba propagarse en otras zonas de la península sin que el gobierno pudiera oponérsele; y que más bien el ministro de Agricultura -obviamente con la conformidad de todo el gobierno- favorecía con leyes y decretos que a esos pequeños propietarios se les desposeyera de sus tierras.

Como es sabido el instrumento básico creado por Ruiz-Funes para que se llevaran a cabo expropiaciones al margen de cualquier disposición que la ley de Reforma Agraria pudiera prever acerca de los límites de la propiedad expropiable, fue el decreto del 20 de marzo de 1936 que, apoyándose en el artículo 44 de la Constitución ${ }^{52}$-que también los socialistas esgrimían en todo momento- permitía la expropiación de toda finca, fuera cual fuera su dimensión, en consideración de la «utilidad social» de sus efectos. Según le explicó el Ministro al diputado Dimas Madariaga, que lamentaba la expropiación también de parcelas de pequeños propietarios, el decreto disponía ser «todas las fincas que hay en todo el territorio nacional, cualquiera que sea la extensión superficial que estas fincas tengan, susceptibles de Reforma Agraria» y que por lo tanto no podía «jamás la extensión superficial de la finca ser un tope para que puedan efectuarse en ella determinados asentamientos». ${ }^{53}$

Menor atención se ha prestado - quizás porque no llegó a transformarse en ley- a la intención, que el Ministro «reveló» en Murcia ya a primeros de abril, de "Convertir en propietarios a gran número de arrendatarios y aparceros»" ${ }^{54}$, que, según se desprende de todo lo que dijo en aquella ocasión, debía de ser mucho mayor del de los «antiguos y pequeños» de los que hablaba el programa del Frente Popular. Sucesivamente sería más claro al ilustrar su proyecto de ley sobre arrendamientos en una conferencia radiofónica:

La Reforma Agraria se refiere a las grandes propiedades y a los grandes arrendamientos; es el complemento obligado de ella en lo que afecta al régimen jurídico de la propiedad crear un instrumento legal que regule la vida de los arrendamientos pequeños [...]. Complemento del sistema de asentamientos establecidos por la ley de Reforma Agraria es el hecho de que puedan convertirse en propietarios los pe-

52 El artículo 44 de la Constitución decía: «La propiedad de toda clase de bienes podrá ser objeto de expropiación forzosa por causa de utilidad social y mediante indemnización, a menos que disponga otra cosa una ley aprobada por los votos de la mayoría absoluta de las Cortes. Con los mismos requisitos la propiedad podrá ser socializada».

53 DSC, 29 de abril de 1936, n. 22, pp. 10-11.

54 El Liberal, 7 de abril de 1936. En su discurso delante de sus correligionarios murcianos, que inauguraban la sede de Izquierda Republicana en la ciudad, el Ministro, refiriéndose a sus planes de convertir a los arrendatarios en propietarios decía: « Esta es la labor que con el Gobierno me propongo realizar y que estuvo en secreto hasta aquí porque quería en Murcia, mi tierra, ofreceros las primicias de mis declaraciones en este aspecto». 
queños arrendatarios y aparceros [...]. Se ha juzgado indispensable amparar en un proyecto el derecho de los colonos a adquirir la propiedad, en ciertas condiciones, siempre con carácter coactivo para el propietario absentista que permanece ajeno a las dificultades y al esfuerzo de la empresa agraria. ${ }^{55}$

Pero la más radical de las medidas forjadas por Ruiz-Funes no interesaba sólo a los «absentistas» sino que a muchos propietarios - de todo tamaño, de toda la península y con independencia del uso que hicieran de sus tierras- a los que la ley de Rescate y Readquisición de Bienes Comunales que empezó a discutirse en las Cortes a primeros de julio, pretendía expropiar para devolver a los ayuntamientos todos los bienes que en el siglo XIX les habían sido sustraídos por el Estado para venderlos a particulares en el cuadro de la así dicha «desamortización civil». La ley era una verdadera locura económica en un sistema capitalista, ya que en principio hundía cualquier empresa agraria, por modélica que fuese, cuya tierra tuviese aquel origen; y en cualquier caso desposeía de su finca un gran número de propietarios, que a menudo la habían adquirido a través de una compra muy posterior a la desamortización, y aunque la cultivaran directamente y su extensión fuera inferior a la de las propiedades destinadas a la expropiación por la Reforma Agraria

Durante el muy encendido debate parlamentario sobre la ley el ministro diría:

Necesitamos pensar que la propiedad más que un derecho es una función y es un deber y bastaría recordar el artículo 44 de la Constitución, el cual da medios no sólo para que entendamos modificada la construcción tradicional del derecho de propiedad, sino para que, manejando el concepto de utilidad social, muchas veces este derecho de propiedad, en colisión con la propia utilidad social, pueda ser vencido por esta última. ${ }^{56}$

Es cierto que la ley preveía que la pequeña propiedad — sin que se especificaran sus límites- quedaría exceptuada de la expropiación. Pero con lo que estaba ocurriendo en el campo, donde a menudo los mismos técnicos del IRA eran coaccionados por los campesinos y su sindicato, no había ninguna garantía de que de hecho ella fuera respetada, sobre todo si sus propietarios no la cultivaban directamente.

La que en realidad se estaba impetuosamente realizando en el campo era una gran expropiación de tierras - que Tuñón de Lara calcula haber interesado ya un millón de hectáreas al estallar la guerra civil ${ }^{57}$ - que sin embargo no afectaba sólo a las grandes propiedades mal aprovechadas — que había bastantes como para asentar gran número de familias campesinas- sino que a muchas más - ya la nueva ley de Reforma Agraria reducía mucho los límites de la propiedad expropiable con respecto a los fijados en la de 1932- en base a criterios que si no eran

55 El Liberal, 29 de abril de 1936.

56 Citado en M. TUÑÓN DE LARA, Tres claves de la Segunda República, op. cit., pp. 189-90.

57 lbid. p. 195. 
directamente revolucionarios como los de los caballeristas en cualquier caso se distanciaban mucho de los liberal-capitalistas.

Ruiz-Funes lo dijo muy claramente al presentar su ley sobre el rescate de las tierras municipales desamortizadas:

Venimos a resucitar los patrimonios rústicos municipales de modo sistemático y reiterado: no somos liberales en economía. No hay nadie que en la hora actual pueda inscribirse ni enrolarse en las doctrinas del liberalismo económico, que significaban un enorme progreso en la obra de Campomanes y Jovellanos, pero que en el momento actual del mondo son instrumentos injustos y estériles. ${ }^{58}$

Es evidente que esas palabras dejaban en gran ansiedad a todos los que aspiraban, cualquier fuese la dimensión y el ramo de su empresa, a quedar en una economía de tipo liberal. Pero la ansiedad se volvía miedo y hasta terror si esas palabras se las asociaba al cuadro de violencias cometidas por los que más decididamente querían salirse de la economía - y de la política - liberal, sin que el gobierno, a pesar de ser regido por unos republicanos que se habían presentado a las elecciones con un programa muy liberal, apareciese capaz de reprimirlas.

Era esta violencia y no la de los terroristas falangistas la que más desestabilizaba la República, sobre todo porque los sectores moderados del electorado de izquierda se sintieron desamparados tanto como los de la derecha, ya que gran parte de los candidatos que aquellos habían votado en masas se encontraban como poseídos por «un espíritu republicano de raigambre revolucionaria» y «pensaban que se trataba de tomar la Bastilla». ${ }^{59}$

Sentimiento de desamparo, miedo, terror, son todos estados de ánimo de esa clase media que a menudo registraban los mayores representantes políticos del Frente Popular. En sus cartas a Cipriano Rivas Azaña habla de gran «anxiedad pública», de "situación de pánico» y de que "el hombre neutro está asustadísimo". ${ }^{60}$ Prieto en su discurso de Bilbao, después de haber recordado el espectáculo de luchas y motines, del desenfreno furioso en pueblos y villas, hablaba del «estado de terror en que se encuentra actualmente la burguesía española», pero sólo para aconsejar que se le aprovechara para «implantar, dentro del molde mismo de la Constitución española, reformas sociales de enorme trascendencia que hagan indestructible para siempre la fuerza del proletariado que dirige el partido socialista». ${ }^{61}$

En esto Prieto se diferenciaba de Caballero sólo por los cauces que pensaba seguir para llegar a una meta que básicamente compartía con su rival. Pero pare-

58 Citado lbid. p. 191.

59 J. AVILÉS FARRÉ, La izquierda burguesa y la tragedia de la II República, Comunidad de Madrid, Madrid 2006, p. 434.

60 C. DE RIVAS CHERIF, Retrato de un desconocido, pp. 672 y 674

61 El Liberal, 26 de mayo de 1936. 
cía no darse cuenta de que aquel terror de la burguesía — que incluía muchas clases medias democráticas- más que para implantar reformas sociales tan trascendentes era aprovechable por los enemigos de toda reforma y de toda democracia. Porque los ciudadanos que, fuese cual fuese el lugar que ocupaban en la escala social, eran contrarios a la revolución, no es que se dejaron impresionar especialmente por uno u otro atentado de derecha o de izquierda, sino que, por el conjunto de lo que veían relativo a política y violencia, pudieron temer que la revolución se estaba ya actuando o estaba a punto de estallar. Así que, activamente o pasivamente, dieron libre paso al golpe, a la guerra civil y al hundimiento de la democracia. 